\title{
Approaches Towards Efficient Use of Boar Semen in the Pig Industry
}

\author{
J Roca, I Parrilla, Heriberto Rodriguez-Martinez, M A Gil, C Cuello, \\ J M Vazquez and E A Martinez
}

\section{Linköping University Post Print}

N.B.: When citing this work, cite the original article.

This is the authors' version of the following article:

J Roca, I Parrilla, Heriberto Rodriguez-Martinez, M A Gil, C Cuello, J M Vazquez and E A Martinez, Approaches Towards Efficient Use of Boar Semen in the Pig Industry, 2011, Reproduction in domestic animals (1990), (46), SI, 79-83.

which has been published in final form at:

http://dx.doi.org/10.1111/j.1439-0531.2011.01828.x

Copyright: Blackwell Publishing http://www.blackwellpublishing.com/

Postprint available at: Linköping University Electronic Press http://urn.kb.se/resolve?urn=urn:nbn:se:liu:diva-71390 
Towards an efficient use of liquid, cryopreserved and sexed semen in the pig industry

Jordi Roca ${ }^{1}$, Inma Parrilla ${ }^{1}$, Heriberto Rodriguez-Martinez ${ }^{2}$, María A. Gil ${ }^{1}$, Cristina Cuello $^{1}$, Juan M. Vazquez ${ }^{1}$, Emilio A. Martinez ${ }^{1}$

${ }^{1}$ Department of Medicine and Animal Surgery, Faculty of Veterinary Science. University of Murcia, E-30100 Murcia, Spain. ²Department of Clinical and Experimental Medicine, Faculty of Health Sciences. Campus HU/US, Developmental biology, Linköping University. SE-581 85 Linköping, Sweden.

\begin{abstract}
The current cervical artificial insemination (CAI) procedure, involving deposition of excessive sperm numbers, is uneconomical for pig industry. The most obvious alternative requires uterine deposition in combination with fixed-time Al, which would reduce the number of sperm required per pregnant sow, thus allowing the best use of valuable boars and, ultimately, the commercial integration of frozen-thawed and sexed sperm. This review depicts possible best ways to implement an efficient use of liquidstored, frozen-thawed and sexed sperm by the pig industry.
\end{abstract}

\title{
Introduction
}

Artificial insemination is extensively used by swine producers worldwide, playing a pivotal role on the improvement of global swine production. The current procedure, cervical artificial insemination (CAI) implies delivery of large sperm numbers (>2-3 billion spermatozoa) into the cervix two or three times per oestrus. Although the fertility outcomes parallel those of natural mating when using fresh or 
liquid-stored semen, the large number of sperm required per pregnant sow ( $>7$ billion) presses the collection frequency for valuable boars. In addition, it restricts the commercial use of frozen-thawed (FT) sperm, and limits the application of sexed sperm, ultimately limiting the economical profitability of valuable sires. Moreover, despite of the high number of sperm delivered via CAI, most of them do not participate in fertilization (Roca et al., 2006), since they are rapidly evacuated from the uterus by backflow during or immediately after Al $30-40 \%$ of the total number of spermatozoa deposited into the cervical canal), trapped and die in the cervical folds (5-10\%) and phagocytized in the uterus (up to $60 \%$ ).

Swine production has become highly competitive, and producers are forced to incorporate breeding methods of higher efficiency and profitability, so that productivity increases alongside with cost-reduction. In this context, decreasing the number of sperm required per pregnant sow should be useful. This review summarizes possible best paths for achieving this goal, still warranting high fertility.

\section{Key approaches}

The primary goal of any Al strategy must be ensure a sufficient sperm number in the oviduct at the time of ovulation for optimal fertilization, irrespectively of the sperm numbers delivered and sperm treatment used. Depositing the spermatozoa deeper into the reproductive tract would allow overcoming some of the weakness of CAI. Consequently, fewer sperm per Al-dose would be required to maintain fertility. Insemination procedures allowing semen delivery into the uterus body (intra-uterine insemination, IUI) and the proximal uterine horn (deep uterine insemination, DUI) are now commercially available for pigs (Roca et al. 2006). In addition, laparoscopy is 
showed as an effective and efficient procedure for delivering very low numbers of expensive or very valuable sperm of limited availability into the utero-tubal junction or the mid-oviduct (Vazquez et al. 2008).

Although uterine insemination procedures can help to achieve a more efficient use of sperm, special emphasis should be placed on how far we can go in reducing sperm numbers per Al-dose. This reduction should never compromise that an optimal competent sperm population reach the oviduct at the time of ovulation. If an insufficient functional sperm population colonizes the oviductal reservoir, partial or no fertilization will happen and consequently the results will be reduced farrowing rates and/or poorer litter sizes. In addition, it is important to bear in mind that as the numbers of sperm per Al-dose is reduced, the influence of other variables in the fertility outcome increase. Variables such as actual functional sperm rate, boar fertility, sow management and timing of sperm delivery should be carefully considered. The relevance of some of these variables will be discussed in other lectures of this Boar Semen Preservation Conference.

The timing of sperm delivery relative to ovulation is always one of the most important variables affecting the overall success of $\mathrm{Al}$, but it becomes more important as the number of sperm delivered is reduced (García et al., 2007b; Pelland et al., 2008). In addition, the optimal timing of $\mathrm{Al}$ is narrowed as delivered spermatozoa grow old or weaker. Therefore, establishment of a window for optimal timing of $\mathrm{Al}$ is the utmost objective. As ovulation usually occurs during the final third part of behavioral oestrus (Soede and Kemp, 1997), accurate detection of the onset of oestrus as well as monitoring its duration, are pre-requisites to properly forecast ovulation under field conditions. If oestrus is sub-optimally detected, ovulation can be synchronized using 
exogenous pharmaceutical treatment. It allows greater accuracy in predicting the timing of ovulation, which also facilitates single fixed-time Al, and, finally, greater reduction of the numbers of sperm per litter. Use of Equine Chorionic Gonadotropin (eCG), administered $24 \mathrm{~h}$ after weaning or of Altrenogest treatment, in combination with human CG (hCG), porcine Luteinizing Hormone (p-LH) or Gonadotropin-Releasing Hormone $(\mathrm{GnRH})$ agonist, $56-80 \mathrm{~h}$ later, is the most effective currently used treatment set-up. For more details of these and other effective hormonal treatments see the recent review of Brüssow et al. (2009).

\section{Liquid stored semen}

Although breeding sows via CAI with only 1 billion sperm per Al-dose can result in acceptable farrowing rate and litter size when inseminated close to ovulation time (Pelland et al., 2008), a minimum of 2.5 billion liquid-stored sperm per CAl-dose is recommended to achieve systematic high fertility (Reicks and Levis, 2008; Alm et al., 2006). This sperm number is far too excessive for an efficient use of valuable sires. Field IUI-trials have showed that 1 billion spermatozoa are enough to mimic outcomes achieved by CAI with 3 billion sperm (Watson and Behan, 2002; Rozeboom et al., 2004). Moreover, the most recent IUI-trial, conducted on Danish commercial farms and involving a total of 9,197 sows, showed high fertility outcome by using only 750 million spermatozoa, when deposited at a correct interval before ovulation (Olesen and Hansen, 2009). A greater lowering of the sperm number affects the reproductive outcomes of inseminated sows, particularly litter size (Rozeboom et al., 2004), this could be related with partial fertilizations. Although IUI for liquid stored semen is currently used by practitioners in several European regions, the sperm numbers per Al- 
dose is not yet standardized. It appears that the threshold dose to achieve systematic high fertility success is at least 1 billion sperm (Roca et al., 2006). However, when farm conditions or sperm quality are sub-optimal, it would seem prudent to use sperm numbers up to 1.5 billion per IUI-dose (Roberts and Bilkei, 2005). If a stronger reduction in sperm number per Al-dose is needed (more profitable use of valuable ejaculates, for instance), then the DUI technique should be used. Although some unilateral fertilization occur, negatively affecting litter size, acceptable fertility outcomes are possible, after delivering in the depth of an uterine horn as few sperm as 150 million (Martinez et al., 2002). Partial fertilizations and consequently small litter sizes are avoided by increasing the number of liquid-stored sperm per DUI-dose to 600 million (Martinez et al., 2006).

Fixed-time Al, single or double, is not usual when liquid-stored semen is used. Currently, sows are bred every $24 \mathrm{~h}$ from the start of oestrus until oestrus is no longer detected, issuing $>2.5$ average number of Al per oestrus (Rozeboom et al., 2004). If two or even just one Al at fixed-time is to be tested, concerns rise. The optimal time for $\mathrm{Al}$ is in the interval from $28 \mathrm{~h}$ before to $4 \mathrm{~h}$ after ovulation (Nissen et al., 1997). However, highest fertility is seen when liquid-stored semen is placed in the reproductive tract within $12-24 \mathrm{~h}$ before ovulation, regardless of the sperm number delivered (Steverink et al., 1997).

\section{Frozen-thawed sperm}

Ideally, frozen-thawed (FT) sperm should be usable for Al given their additional advantages respect to liquid-stored semen (Bailey et al., 2007). Despite this, they are yet scarcely used by the swine industry, being its only use transferring valuable genetic 
material (Tribout et al., 2010). Its low fertility success compared to liquid-stored semen remains the burden of FT-semen when attempting integration in commercial swine Al programs. Field CAl-trials (Table 1) with fertility success similar to those with liquidstored semen; e.g. with farrowing rates over $80 \%$ and more than 10 piglets born per litter (Eriksson et al. 2002; J. Roca, unpublished observations), have clearly rebutted this myth. These optimal fertility results were achieved in sows CAl-inseminated 2-3 times per oestrus with 5-6 billion total sperm per Al-dose $(\approx 2-3$ billion motile spermatozoa per dose). The biological reason of this large number of sperm per Aldose would be related to weakness of FT-sperm, which are especially vulnerable during their transit through the long pig female reproductive tract. In fact, the number of functionally FT-spermatozoa available in the oviduct is usually 10-fold lower compared to fresh semen, even delivering double FT-sperm number (Wabersky et al., 1994). In comparison to liquid-stored semen, 4-6 times more FT-sperm are required per oestrus, implying few Al-doses prepared per ejaculate, a non-economical situation. Attempts have been made to reduce the number of FT-sperm required for a successful CAl insemination, with encouraging results. Recently, Thilmant (2009) reported farrowing rates over $90 \%$ with more than 12 piglets born per litter in sows CAIinseminated with 2.5 billion motile spermatozoa per Al-dose. In despite of these promising fertility results, the number of motile spermatozoa is still too large, considering that the percentage of motile spermatozoa after thawing barely reaches over 60\% (Rath et al., 2009), being close to previous trials (see Table 1). Therefore, the immediate use of FT-spermatozoa on commercial Al requires the drastic reduction of total sperm numbers to that needed to produce optimum litter size. Uterine Al techniques are an alternative to CAl for lowering sperm numbers per Al. To the 
authors' knowledge, few field trials have been published evaluating the potential effectiveness of IUI for FT-sperm, and fertility outcomes are not too encouraging (Abad et al., 2007; Casas et al., 2009). For instance, in a recent on farm study conducted in Belgium, IUI-doses of 1 billion motile sperm resulted in $60 \%$ of farrowing rate compared with $91.7 \%$ when CAI-inseminated with 3.6 billion motile sperm (Thilmant, 2009). In contrast, DUI offers optimistic possibilities to an effective and efficient use of FT-sperm, achieving farrowing rates over $80 \%$ when inseminating as few total sperm as 1 billion (Bolarin et al., 2006; Bathgate et al., 2008).

Frozen-thawed boar sperm have a shortened fertile lifespan $(<8$ h) once delivered in the female reproductive tract (Waberski et al., 1994; Wongtawan et al., 2006). Therefore, it is a common practice to inseminate sows three or, even, four times per estrous with the aim that one of them will fall inside the narrow window for optimal fertility. However, efficient semen usage call for breeding protocols with only double or even single fixed-time Al (Spencer et al., 2010). For them, sperm should be delivered within a short period of time before expecting ovulation time, which requires accurate knowledge of when ovulation occurs, being hormonal treatment advised to achieve it (Roca et al., 2003). In this context, a single DUI with 1 billion FT-spermatozoa ( $\approx$ 500-650 million live spermatozoa per dose) can achieve high fertility outcomes (farrowing rates over $80 \%$ with more than 10 piglets born per litter), comparable to liquid semen, if deposited close to the beginning of the ovulation (Bolarin et al., 2006; 2009). However, it is important to notice that a second fixed-time Al or doubling sperm numbers in single fixed-time Al partially compensates some variations in the expected time of ovulation (Bolarin et al., 2006; Spencer et al., 2010). 


\section{Sex-sorted spermatozoa}

The advantages of using sex-sorted spermatozoa in Al-programs open a new dimension to pig industry. Sexed sperm has in itself the potential to substantially speed-up the rate of swine genetic progress when implemented as part of an Al program (Rath and Johnson, 2008). The still low speed of sorting (Sharpe and Evans, 2009) together with the short lifespan of liquid-stored- (Parrilla et al., 2005; Spinaci et al., 2010) and FT- (Bathgate, 2008) sorted sperm are obstacles to overcome towards a field application of sex-sorted spermatozoa. Deep uterine insemination has been postulated as the most suitable Al technique for producing litter size from bulk-sorted (Vazquez et al., 2003) and sex-sorted non-frozen sperm (Rath et al., 2003; Grossfeld et al., 2005), using as few as 50 million sperm. However, this is still a too large a number of sperm per DUI-dose (considering the current outcomes and losses of the sorting procedure) which, together with the low fertility rates so far achieved (up to $60 \%$ ), limits the current possibilities for DUI as an efficient insemination tool for on-farm application of sexed sperm. Nevertheless, DUI will be attractive in the future as increasing sorting rates and extending lifespan of sorted sperm. Nowadays, the laparoscopy insemination technique, despite its high cost and skill requirements, offers to the pig industry a possibility for an efficient application of sexed sperm. The suitability of the laparoscopic technique to inseminate pig females was initially evaluated using fresh semen (Fantinati et al., 2005) and then successfully extrapolated to sex-sorted sperm (Garcia et al., 2007a). The procedure involving the direct delivery of spermatozoa into the utero-tubal junction and/or into the oviduct can be speedily performed (between 9 and $21 \mathrm{~min}$, with an average of $12.6 \pm 0.6 \mathrm{~min}$ in 27 sows; I. Parrilla, personal communication). Careful laparoscopic manipulation of the 
reproductive tract did not have negative consequences to the future reproductive performance of the sows (Parrilla et al., 2010). Preliminary results (87 sows) of current experiments in our laboratory, showed that fertility rates over $70 \%$ and litter size as large as 10 piglets born, can be obtained with a single laparoscopic insemination delivering at optimal timing between 1 and 3 million liquid-stored sexed sperm per sow.

Similar to FT-sperm, the fertility outcomes of sexed sperm depend highly on the timing relative to ovulation (Vazquez et al., 2008). Although the lifespan of liquidstored and FT-sexed sperm are still not well defined, it is apparently very short, considering that the highest fertility is achieved only when sperm is laparoscopically delivered shortly before ovulation. Therefore, hormonal treatments for accurate prediction of ovulation are required, and high eCG dosage (1500 IU) is advised to avoid possible small litter size related to recurrent unilateral or partial fertilizations (Garcia et al., 2007a). Sperm delivery at ovulation time or later, results in fertility loss related to a high incidence of polyspermy (Vazquez et al., 2006).

\section{Conclusions and remarks}

Uterine insemination procedures have shown to be beneficial for the efficient use of low numbers of liquid stored and frozen-thawed spermatozoa, achieving optimal farrowing rates and litter sizes using as few as $\approx 1$ billion sperm per Al-dose. Laparoscopic insemination has enabled satisfactory fertility outcomes after insemination with 1-3 million liquid-stored sexed sperm. However, fertility success depends on proper timing of semen deposition relative to ovulation rather than on the site and number of sperm deposed. Therefore, convenient and economical protocols 
to synchronize ovulation are needed for a profitable use of boar spermatozoa, particularly to frozen-thawed and sexed sperm, where single fixed-time Al should be required for efficiency.

The number of sperm required per litter size can define the cost-effectiveness of any insemination strategy. However, it should be more properly defined at farrowing, in terms of fecundity index, and at weaning where the average piglets weaning weight could be a better estimation, particularly when the ultimate goal of Al is to increase the impact of individual valuable boars on genetic progress.

\section{Acknowledgments}

The authors acknowledge the Seneca Foundation of Murcia (GERM 04543/07) and the Spanish Ministry of Science and Innovation (AGL2008-04127/GAN) for their support on some of the published and unpublished data presented in this review.

\section{References}

Abad M, Garcia JC, Sprecher DJ, Cassar G, Friendship RM, Buhr MM, Kirkwood RN, 2007: Effect of insemination-ovulation interval and addition of seminal plasma on sow fertility to insemination of cryopreserved sperm. Reprod Domest Anim 42, 418-422.

Alm K, Peltoniemi OAT, Koskinen E, Andersson M, 2006: Porcine field fertility with two different insemination doses and the effect of sperm morphology. Reprod Dom Anim 41, 210-213.

Bailey JL, Lessard C, Jacques J, Brèque C, Dobrinski I, Zeng W, Galantino-Homer HL, 2008: Cryopreservation of boar semen and its future importance to the industry. Theriogenology 70, 1251-1259. 
Bathgate R, 2008: Functional integrity of sex-sorted, frozen-thawed boar sperm and its potential for artificial insemination. Theriogenology 70, 1234-1241.

Bathgate R, Eriksson BM, Thomson PC, Maxwell WM, Evans G, 2008: Field fertility of frozen-thawed boar sperm at low doses using non-surgical, deep uterine insemination. Anim Reprod Sci 103, 323-335.

Bolarin A, Hernandez M, Vazquez JM, Rodriguez-Martinez H, Martinez EA, Roca J, 2009: Use of frozen-thawed semen aggravates the summer-autumn infertility of artificially inseminated weaned sows in the Mediterranean region. J Anim Sci 87, 39673975.

Bolarin A, Roca J, Rodriguez-Martinez H, Hernandez M, Vazquez JM, Martinez EA, 2006: Dissimilarities in sows' ovarian status at the insemination time could explain differences in fertility between farms when frozen-thawed semen is used. Theriogenology 65, 669-680.

Brussow K-P, Schneider F, Kanitz W, Ratky J, Kauff old J, Wahner M, 2009: Studies on fixed-time ovulation induction in the pig. In: Control of Pig Reproduction VIII, Eds. H. Rodriguez-Martinez, J.L. Vallet and A.J. Ziecik, Nottingham Univ. Press, Nottingham, UK, Soc Reprod Fertil Suppl 66, 187-195.

Casas I, Sancho S, Briz M, Pinart E, Bussalleu E, Yeste M, Bonet S, 2010: Fertility after post-cervical artificial insemination with cryopreserved sperm from boar ejaculates of good and poor freezability. Anim Reprod Sci 118, 69-76.

Eriksson BM, Petersson H, Rodriguez-Martinez H, 2002: Field fertility with exported boar semen frozen in the new FlatPack container. Theriogenology 58, 1065-1079. 
Fantinati P, Zannoni A, Bernardini C, Webster N, Lavitrano M, Forni M, Seren E, Bacci ML, 2005: Laparoscopic insemination technique with low numbers of spermatozoa in superovulated prepuberal gilts for biotechnological application. Theriogenology 63, 806-817.

Garcia EM, Vazquez JM, Parrilla I, Calvete JJ, Sanz L, Caballero I, Roca J, Vazquez JL, Martinez EA, 2007a: Improving the fertilizing ability of sex sorted boar spermatozoa. Theriogenology 68, 771-778.

Garcia JC, Abad M, Kirkwood RN, 2007b: Effect of sperm numbers and time of insemination relative to ovulation on sow fertility. Anim Reprod Sci 100, 397-401.

Grossfeld R, Klinc P, Sieg B, Rath D, 2005: Production of piglets with sexed semen employing a non-surgical insemination technique. Theriogenology 63, 2269-2277.

Martinez EA, Vazquez JM, Roca J, Lucas X, Gil MA, Parrilla I, Vazquez JL, Day BN, 2002: Minimal sperm number for normal fertility after deep intrauterine insemination in non-sedated sows. Reproduction 123, 167-170.

Martínez EA, Vazquez JM, Parrilla I, Cuello C, Gil MA, Rodríguez-Martinez H, Roca J, Vazquez JL, 2006: Incidence of unilateral fertilizations alter low dose deep intrauterine insemination in spontaneously ovulating sows under field conditions. Reprod Dom Anim 41, 41-47.

Nissen AK, Soede NM, Hyttel P, Schmidt M, D'Hoore L, 1997: The influence of time of insemination relative to time of ovulation on farrowing frequency and litter size in sows, as investigated by ultrasonography. Theriogenology 47, 1571-1582.

Olesen AK, Hansen C, 2009: Intrauterine insemination of sows by using a two-chamber semen bag system. In: Control of Pig Reproduction VIII, Eds. H. Rodriguez-Martinez, J.L. 
Vallet and A.J. Ziecik, Nottingham Univ. Press, Nottingham, UK, Soc. Reprod Fertil Suppl $66,81-82$.

Parrilla I, Gil MA, Cuello C, Sanchez-Osorio J, Del Olmo D, Gomis J, Maside C, Roca J, Vazquez JL, Martinez EA, Vazquez JM, 2010: Effect of intra-oviductal laparoscopic manipulation on future reproductive performance of sows. Reprod Dom Anim 45(s3), 102.

Parrilla I, Vazquez JM, Gil MA, Caballero I, Almiñana C, Roca J, Martinez EA, 2005: Influence of storage time on functional capacity of flow cytometrically sex-sorted boar spermatozoa. Theriogenology 64, 86-98.

Pelland C, Cassar G, Kirkwood R, Friendship R, 2008: Fertility after intrauterine insemination with conventional or low numbers of spermatozoa in sows with synchronized ovulation. Swine Health Prod 16, 188-192.

Rath D, Bathgate R, Rodriguez-Martinez H, Roca J, Strzezek J, Waberski D, 2009: Recent advances in boar semen cryopreservation. In: Control of Pig Reproduction VIII, Eds. H. Roberts PK, Bilkei G, 2005: Field experiences on post-cervical artificial insemination in the sows. Reprod Domest Anim 40, 489-491.

Rodriguez-Martinez, J.L. Vallet and A.J. Ziecik, Nottingham Univ. Press, Nottingham, UK, Soc. Reprod Fertil Supp 66, 51-66.

Rath D, Johnson LA, 2008: Application and commercialization of flow cytometrically sex-sorted semen. Reprod Domest Anim 43, 338-346.

Rath D, Ruiz S, Sieg B, 2003: Birth of female piglets following intrauterine insemination of a sow using flow cytometrically sexed boar semen. Vet Rec 152, 400-401. 
Reicks DL, Levis DG, 2008: Fertility of semen used in commercial production and the impact of sperm numbers and bacterial counts. Theriogenology 70, 1377-1379.

Roca J, Carvajal G, Lucas X, Vazquez JM, Martinez EA, 2003: Fertility of weaned sows after deep intrauterine insemination with a reduced number of frozen-thawed spermatozoa. Theriogenology 60, 77-87.

Roca J, Vazquez JM, Gil MA, Cuello C, Parrilla I, Martinez EA, 2006: Challenges in pig artificial insemination. Reprod Domest Anim 41(s2), 43-53.

Rozeboom KJ, Reicks DL, Wilson ME, 2004: The reproductive performance and factors affecting on-farm application of low-dose intrauterine deposit of semen in sows. J Anim Sci 82, 2164-2168.

Sharpe JC, Evans KM, 2009: Advances in flow cytometry for sperm sexing. Theriogenology 71, 4-10.

Soede NM, Kemp BK, 1997: Expression of oestrus and timing of ovulation in pigs. J Reprod Fertil Suppl 52, 91-103.

Spencer KW, Purdy PH, Blackburn HD, Spiller SF, Stewart TS, Knox RV, 2010: Effect of number of motile, frozen-thawed boar sperm and number of fixed-time inseminations on fertility in estrous-synchronized gilts. Anim Reprod Sci 121, 259-266.

Spinaci M, Vallorani C, Bucci D, Bernardini C, Tamanini C, Seren E, Galeati G, 2010: Effect of liquid storage on sorted boar spermatozoa. Theriogenology 74, 741-748.

Steverink DWB, Soede NM, Bouwman EG, Kemp B, 1997: Influence of inseminationovulation interval and sperm cell dose on fertilization in sows. J Reprod Fertil 111, 165171. 
Thilmant P, 2009: Cryopreservation on pig semen: update and critical steps. Proceeding of Annual Meeting of the EU-AI-Vets, 27-31. Ghent, Belgium.

Tribout T, Caritez JC, Gruand J, Bouffaud M, Guillouet P, Billon Y, Pery C, Laville E, Bidanel JP, 2010: Estimation of genetic trends in French Large White pigs from 1977 to 1998 for growth and carcass traits using frozen semen. J Anim Sci 88, 2856-2867.

Vazquez JM, Martinez EA, Parrilla I, Cuello C, Gil MA, Garcia E, Caballero I, Alminñana C, Roca J, Vazquez JL, 2006: Improving the efficiency of laparoscopic intraoviductal insemination with sex-sorted boar spermatozoa. Reprod Fertil Dev 18, 283.

Vázquez JM, Martinez EA, Parrilla I, Roca J, Gil MA, Vazquez JL, 2003: Birth of piglets after deep intrauterine insemination with flow cytometrically sorted spermatozoa. Theriogenology 59, 1605-1614.

Vazquez JM, Parrilla I, Gil MA, Cuello C, Caballero I, Vazquez JL, Roca J, Martinez EA, 2008: Improving the efficiency of insemination with sex-sorted spermatozoa. Reprod Domest Anim 43(s4), 1-8.

Waberski D, Weitze KF, Gleumes T, Schwartz M, Willmen T, Petzold R, 1994: Effect of time of insemination relative to ovulation on fertility with liquid and frozen boar semen. Theriogenology 42, 831-840.

Watson PF, Behan JR, 2002: Intrauterine insemination of sows with reduced sperm numbers: results of a commercially based field trial. Theriogenology 57, 1683-1693.

Wongtawan T, Saravia F, Wallgren M, Caballero I, Rodriguez-Martinez H, 2006: Fertility after deep intra-uterine artificial insemination of concentrated low-volume boar semen doses. Theriogenology 65, 773-787. 